\title{
PANDANGAN HUKUM ISLAM TENTANG DENDA AKIBAT PEMBATALAN PINANGAN (KHITBAH) OLEH PIHAK PEREMPUAN
}

\author{
Fathullah*
}

\begin{abstract}
Khitbah or application or proposal is a preliminary or pre-marriage period between a man and a woman, as a first step before the two carry out the marriage contract, so that each knows the candidate. The sermon itself must still be answered "yes" or "no". If it has been answered "yes", then be the woman as "makhtubah" or the woman who is officially applied. In connection with this engagement in society there is a habit at the time of its implementation, the prospective bridegroom gives a gift such as jewelry, money, food and produce as a sign that someone really intends to continue the marriage stage. the consequences of giving the prize are different from giving in the form of dowry

Giving a grant that is not halal withdraws the grant, if he gives a grant voluntarily (charity), not for compensation. While the grantor who still has the right to withdraw the grant, if the grant is given in return for something that will be received, but he does not get it.
\end{abstract}

Keyword: Islamic Law, Khitbah, Islamic Law

* Dosen Institut Ilmu Keislaman Zainul hasan Genggong Kraksaan 


\section{PEMBAHASAN}

\section{A. Khitbah (Pinangan/Lamaran )}

\section{Pengertian Khitbah (Pinangan/Lamaran )}

Pada ilmu fikih kata khitbah disebut juga lamaran, berasal dari kata1: خطب - يخطب - خطبا. Kata lamaran dalam hukum Islam adalah

$$
\text { طلبها للزواج با لوسيلة المعروفة بين الناس }
$$

Artinya:"Seseorang pria meminta kepada seseorang wanita untuk menjadi isterinya dengan cara-cara yang berlaku diantara masyarakat"."

Secara terminologi fikih, khitbah atau lamaran atau pinangan merupakan pendahuluan atau masa pra perkawinan antara seorang pria dengan seorang wanita, sebagai langkah awal sebelum keduanya melaksanakan akad nikah, agar masing-masing mengenal calonnya. Khitbah itu sendiri masih harus dijawab "ya" atau " tidak". Bila telah dijawab "ya", maka jadilah wanita tersebut sebagai " makhtubah" atau wanita yang resmi dilamar. ${ }^{3}$

Meminang atau melamar adalah menyatakan permintaan atau ajakan mengingat perjodohan dari seorang laki-laki kepada seorang wanita untuk menjadi istrinya dengan cara yang sudah berlaku dalam masyarakat. Meminang adalah usaha dalam pendahuluan dalam rangka pernikahan. Sebelum dilangsungkan pernikahan, kedua belah pihak harus saling mengenal baik sifat maupun pembawaan, kemudian menarik persamaan dan perbedaan sehingga nanti setelah menikah kedua belah pihak terjadi saling menghargai perbedaan, sama-sama mau berkorban untuk yang lainnya. ${ }^{4}$

Sehingga diharapkan akad nikah yang mereka lakukan benarbenar atas dasar kerelaan, suka sama suka dan dengan pandangan yang jauh, dengan demikian perkawinannya dapat berlangsung kekal tak mudah putus dan diputuskan. ${ }^{5}$ Dalam Kompilasi Hukum Islam (KHI)

\footnotetext{
1 Muhammad Yunus, Kamus Arab Indonesia, Jakarta: PT. Hidakarya Agung, hlm. 118

2 Sayyid Sabiq, Fiqh Sunnah, Juz II, al-Fatkhu lil-I'alm al-Araby, t.t., hlm. 138

3 http://www.kompasiana.com. Diakses 01 Mei 2019

4 Labib MZ. Konsep Perkawinan dalam Islam. Surabaya : Putra Jaya.2007. hal 25

5 Hadi Mufa'at Ahnad, Fikih Munakahat (Hukum Perkawinan Islam dan Beberapa Permasalahannya), Duta Grafika, 1992, hlm.31.
} 
mengartikan khitbah sebagai kegiatan kearah terjadinya hubungan perjodohan antar seorang pria dengan wanita. ${ }^{6}$ Kegiatan Peminangan dimaksudkan supaya masing-masing pihak dapat mengenal pribadi dan identitas calon suami atau istri sesuai dengan langkah-langkah yang di gariskan oleh syara'.

\section{B. Tujuan dan Hikmah Khitbah (Pinangan/lamaran)}

1. Tujuan Khitbah (Pinangan)

Adapun tujuan khitbah di antaranya:

a. karena ingin menjamin perkawinan yang di kehendaki itu sudah dapat dilangsungkan dalam waktu dekat.

b. Sekedar untuk membatasi pergaulan kedua belah pihak yang telah di ikat.

c. Memberi kesempatan kedua belah pihak untuk saling lebih mengenal sehingga kelak mereka sebagai suami istri menjadi satu pasangan yang harmonis.

2. Hikmah Khitbah (pinangan)

Agar lancar kegiatan khitbah (pinangan) ini, pelamar di perkenankan melihat dan berkenalan dengan wanita yang ia kehendaki, supaya mereka dapat saling memahami pribadi masing-masing dan dapat mengerti kelebihan dan kekurangan masing-masing yang berupa material maupun imaterial. Setelah proses ini mereka diharapkan semakin mantap untuk menuju kejenjang perkawinan, sehingga kelak dapat di hindari hal-hal yang tidak diharapkan. ${ }^{7}$

\section{Dasar Hukum Khitbah (Pinangan/lamaran)}

Khitbah (pinangan) dalam hukum Islam bukan merupakan hal yang wajib dilalui, setidaknya merupakan suatu tahap yang lazim pada setiap yang akan melangsungkan perkawinan. Tetapi prakteknya dimasyarakat menunjukkan bahwa peminangan merupakan suatu hal yang hampir pasti di lakukan, sehingga seolah-olah masyarakat menganggap bahwa

${ }^{6}$ Abdurrahman, Kompilasi Hukum Islam di Indonesia, Bandung: Aka Press, 1980, hlm.114.

7 Abdul Hadi, Fiqih Munakahat, Semarang: Duta Grafika, Seri I, 1989, hlm.27. 
khitbah merupakan hal yang wajib dilakukan. Hal ini sejalan dengan pendapat Dawud al-Dzahiry yang menyatakan meminang hukumnya wajib. $^{8}$

Adapun Khitbah (pinangan) ada dua bentuk yaitu;

1. Khitbah (pinangan) cara terang-terangan

Kegiatan pinangan secara terang-terangan artinya pihak laki-laki menyatakan niatnya untuk mengawininya dengan permohonan yang jelas atau terang. Misalnya ; aku ingin mengawinimu. Hal ini dapat dilakukan terhadap wanita yang habis masa idahnya dan wanita yang masih sendiri statusnya. ${ }^{9}$

2. Khitbah (pinangan) secara sindiran (kinayah) artinya peminang dalam mengungkapkan keinginannya tidak menggunakan kalimat yang jelas yang dapat dipahami. Misalnya; kamu sudah sepantasnya untuk kawin. ${ }^{10}$ Allah SWT berfirman :

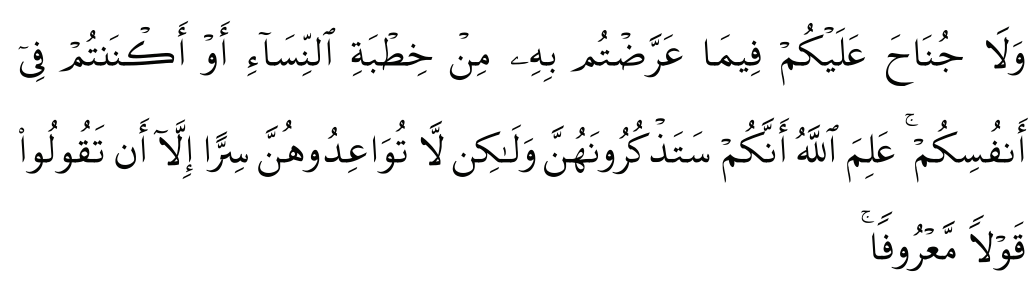

Artinya: Dan tidak ada dosa bagi kamu meminang wanita-wanita itu dengan sindiran atau kamu Menyembunyikan (keinginan mengawini mereka) dalam hatimu. Allah mengetahui bahwa kamu akan menyebut-nyebut mereka, dalam pada itu janganlah kamu Mengadakan janji kawin dengan mereka secara rahasia, kecuali sekedar mengucapkan (kepada mereka) Perkataan yang ma'ruf. ${ }^{11}$

Penjelasan mengenai ayat di atas adalah perempuan yang dalam iddah karena di tinggal mati oleh suaminya. Dan yang dimaksud sindiran

${ }^{8}$ Ibnu Rusyd, Bidayah al Mujtaid, jilid II, (terj), Semarang: Usaha Keluarga, t.th.,hlm.2.

9 Abdul Hadi, Fiqih Munakahat, Semarang: Duta Grafika, Seri I, 1989, hlm.26

${ }_{10}$ Wahbah al-Zuhaily, al Fiqh al-Islam wa Adzilatuhu, Juz VII, Beirut: Dar al Fikr, t.t., hlm.10.

${ }^{11}$ QS. Albaqoroh : 235; [148] Yang suaminya telah meninggal dan masih dalam 'iddah. [149] Wanita yang boleh dipinang secara sindiran ialah wanita yang dalam 'iddah karena meninggal suaminya, atau karena Talak bain, sedang wanita yang dalam 'iddah Talak raji'i tidak boleh dipinang walaupun dengan sindiran. [150] Perkataan sindiran yang baik. 
disini adalah seseorang yang mengucapkan kata yang tersurat berlainan dengan tersiratnya. Seperti ucapan, "engkau wanita yang cantik, atau saya mengharapkan sekali kiranya Allah memudahkan jalan bagiku memperoleh istri yang cantik." ${ }^{12}$. termasuk meminang secara sindiran adalah memberikan hadiah pada perempuan yang dalam iddah.

\section{Syarat dan Halangan Khitbah (Peminangan/lamaran)}

Para Ulama fikih mensyaratkan bagi laki-laki yang hendak meminang wanita agar memperhatikan dua syarat:

a. Syarat mustahsinah

Mustahsinah adalah syarat yang berupa anjuran kepada seorang laki-laki yang akan meminang wanita agar ia meneliti lebih dahulu yang akan dipinangnya itu, apakah sesuai dengan keinginannya atau belum, sehingga hal ini dapat menjamin kelangsungan hidup berumah tangga kelak. ${ }^{13}$ Adapaun syarat mustahsinah yaitu :

1) wanita yang di pinang itu hendaklah setara (sekufu) dengan laki-laki yang meminangnya, seperti sama-sama baik bentuknya, sama-sama berilmu dan sebagainya.

2) wanita yang dipinang itu hendaklah mempunyai sifat kasih sayang dan bisa memberikan keturunan.

3) Wanita yang akan dipinang itu sebaiknya jauh hubungan darahnya dengan laki-laki yang meminangnya. Karena agama melarang seorang laki-laki mengawini seorang wamita yang sangat dekat hubungan darahnya. ${ }^{14}$

4) Sebaiknya mengetahui keadaan jasmani, budi pekerti dan sebagainya dari wanita yang dipinang, sebaliknya wanita yang dipinang harus mengetahui pula keadaan orang yang meminangnya. ${ }^{15}$ hlm.37.

${ }^{12}$ Sayid Sabiq, Fiqih Sunah (Terjemah M. Tholib), Bandung: PT. Al Maarif, 1980, hlm.36

${ }^{13}$ Sayid Sabiq, Fiqih Sunah (Terjemah M. Tholib), Bandung: PT. Al Maarif, 1980,

${ }^{14}$ Djaman Nur, Fikih Munakahat, Semarang: Dina Utama, 1993, hlm.15.

${ }^{15}$ Kamal Mukhtar, Asas-asas Hukum Islam Tentang Perkawinan, Jakarta: Bulan Bintang, 1993, hlm.30. 
b. Syarat lazimah

Makna lazimah adalah syarat yang wajib dipenuhi sebelum peminangan dilakukan. ${ }^{16}$ Adapun syarat lazimah yaitu :

1) Perempuan yang boleh dipinang dengan sindiran atau terus terang, yaitu perempuanyang bukan istri orang, bukan dalam masa iddah (menunggu) dan bukan dalam pinangan orang lain. Jika perempuan yang dipinang orang lain tersebut jelas telah menolaknya, maka bolehlah ia meminang perempuan orang lain. Hadits Nabi Muhammad SAW : Dari Uqban bin Amir, ia berkata bahwa nabi Muhammad SAW bersabda : "orang mukmin dengan orang mukmin yang lainnya itu bersaudara. Janganlah seorang kalian diantara kamu meminang pinangan saudaranya, kecuali pinangan sebelumnya meninggalkan pinangan itu atau memberikan izin kepadanya". ${ }^{17}$

Hadits nabi SAW :

$$
\text { لا يخطب احدك على خطبة حتى يترك الخاطب قبله او يأذن له (متفق عليه) }
$$

Artinya: Janganlah seseorang dari kamu meminang (wanita) yang dipinang saudaranya, sehingga peminang sebelumnya meninggalkannya atau lebih mengijinkannya. ${ }^{18}$

2) Perempuan yang tidak boleh dipinang, baik secara sindiran apalagi dengan terus terang, yaitu perempuan dalam status istri orang lain atau masih dalam iddah raj'I karna suaminya masih berhak merujuknya. Allah SWT berfirman :

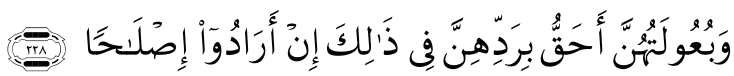

Artinya : dan suaminya lebih berhak merujukinya dalam masa menanti itu, jika mereka (para suami) yang menghendaki ishlah.' ${ }^{19}$

3) Perempuan yang boleh dipinang, yaitu perempuan yang bukan dalam masa iddah raj'i. dalam hal ini dibagi menjadi tiga yaitu :

${ }^{16}$ Ibid hal. 33

${ }^{17}$ HR. Imam Bukhori dan Muslim

${ }^{18}$ HR. Mutafaq 'Alaih

${ }^{19}$ QS. Albaqoroh: 228 
- Perempuan yang dalam masa iddah karena ditinggal mati oleh suaminya, boleh dipinang sendirian, tetapi tidak boleh secara terang-terangan.

- Perempuan beriddah talaq tiga ( ba'in qubro)

- Perempuan beriddah karena talq ba'in sughro atau sebab fasakh.

Ayat diatas dapat diambil kesimpulan bahwa wanita yang karena suaminya meninggal dan iddah thalaq bain boleh dipinang dengan kinayah (sindiran).

Dari uraian diatas dapat diambil suatu pemahaman, bahwa wanita yang statusnya berbeda dari penjelasan diatas, maka haram hukumnya bagi laki-laki untuk meminangnya. Karena syarat diatas menjadi halangan peminangan.

\section{E. Sunnah dalam Khitbah (pinangan/lamaran)}

Laki-laki disunnahkan melakukan hal-hal berikut :

1. Melihat pinangan

Ada dua cara melihat wanita yang akan dipinang yaitu :

a) Mengirim seorang wanita yang dipercaya untuk mengecek keadaan wanita yang mau dipinang. Baik dari sifat,akhlak serta penampilan setiap hari.

b) Seorang laki-laki yang ingin melamarnya langsung. Berasarkan hadits Nabi SAW :

$$
\text { انظر اليها فانه احري ان يؤدم بينكا (ابن ماجه والترمذي) }
$$

Artinya: "Lihatlah. Karena dengan melihat itu akan lebih dijamin dapat menyatukan kamu berdua." (H.R. Ibnu Majah dan Turmudi)."20

Para Jumhur ulama' berpendapat bahwa seorang laki-laki disunahkan melihat calon istri pada bagian wajah dan telapak tangan, dengan begitu akan diketahui kehalusan tubuh dan kecantikannya

Sekalipun para ulama' sepakat tentang kebolehan melihat ini,

${ }^{20}$ HR. 25 Abdullah Muhammad bin Yazid, Sunan Ibnu Majah, Juz I, Beirut: Dar al Fikr, t.t., hlm.585 
tetapi mereka memberikan batasan terhadap apa saja yang boleh dilihat pada diri wanita itu, dalam hal ini mereka berbeda pendapat mengenai batasan-batasan ini.

2. Khutbah

Sunnat-sunnat meminang adalah sebagai berikut : ${ }^{21}$

a. Bagi peminang atau wakilnya menyampaikan khutbah sebelu meminang atau sebelum akad nikah, dimulai dengan memuji Allah dan Sholawat atas Nabi. Didasarkan pada pada hadits nabi SAW :

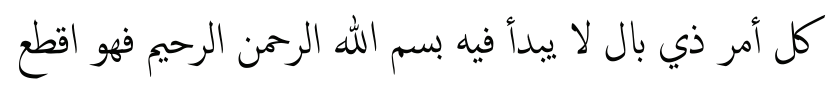

Tiap-tiap perkara penting yang tidak dimulai dengan memuji Allah, maka akan terputus (dari rahmat Allah). ${ }^{22}$

b. Setelah selesai memuji Allah dan bersholawat, dilanjutkan dengan menasehatkan supaya bertaqwa kepada Allah.

c. Kemudian, nyatakanlah keinginannya. Contoh :"aku datang kepada tuan-tuan untuk meminang putri tuan yang mulia".

d. Bagi wali yang dipinang juga menyampaikan khutbah dengan memulai memuji Allah dan bersholawat atas Nabi, dilanjutkan dengan membri nasehat. Kemudian menyatakan menerima. Contoh : "kami tidak keneratan menerima engkau".

\section{F. Akibat Hukum Khitbah (Pinangan/Lamaran)}

Kegiatan khitbah (pinangan/lamaran) merupakan janji akan menikah. Oleh karena itu pertunangan dapat diputuskan oleh salah satu pihak, karena akad dari pertunangan ini belum mengikat salah satu pihak dan belum pula menimbulkan adanya kewajiban yang harus dipenuhi. Akan tetapi menurut Wahbah Zuhaily (Guru besar Universitas Damaskus), berpendapat bahwa akhlaq Islam menuntut tanggung jawab setiap tindakan. Apalagi yang sifatnya yang berkaitan dengan perkawinan. Seorang muslim berkewajiban menunaikan janji yang telah di buatnya. ${ }^{23}$ Firman Allah SWT :

${ }^{21}$ Labib MZ. Konsep Perkawinan dalam Islam. Surabaya : Putra Jaya.2007. hal 25

${ }^{22}$ HR. Ibnu Majah bab Khutbatun Nikah No. 1894)

${ }^{23}$ Wahbah al-Zuhaily, al Figh al-Islam wa Adzilatuhu, Juz VII, Beirut: Dar al Fikr, t.t., hlm.25 


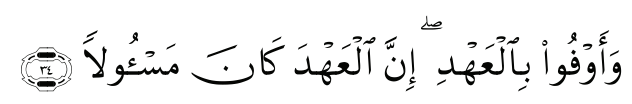

Artinya: Dan penuhilah janji; Sesungguhnya janji itu pasti diminta pertanggungan jawabnya. ${ }^{24}$

Oleh karena itu pemutusan pertunangan dilandasi oleh alasan yang rasional dan kuat. Berkaitan dengan pertunangan ini dalam masyarakat terdapat kebiasaan pada waktu pelaksanaannya, calon mempelai lakilaki memberikan suatu pemberian seperti perhiasan, uang, makanan serta hasil bumi sebagai tanda bahwa seseorang tersebut sungguhsungguh berniat untuk melanjutkan kejenjang perkawinan. Pemberian ini berbeda dengan mahar. Mahar adalah pemberian dari calon suami kepada istri dengan sebab nikah. Akan tetapi pemberian ini termasuk dalam pengertian hadiah. Oleh karena itu akibat yang ditimbulkan oleh pemberian hadiah tersebut berbeda dengan pemberian dalam bentuk mahar.

Ketika pertunangan harus diputuskan, sedangkan pihak lakilaki telah memberikan hadiah atau lainnya kepada siwanita, maka dalam melihat status hukum hadiah ini terdapat perbedaan pendapat dikalangan ulama'.

Para Ulama' Hanafi mengatakan bahwa hadiah itu sama statusnya dengan hibah. Dan orang yang memberikan hibah itu dapat mencabut kembali hibahnya kecuali ada halangan tentang pencabutannya, seperti barang itu sudah habis. Bila barang yang di hibahkan atau di hadiahkan laki-laki itu masih utuh, maka ia boleh meminta kembali. ${ }^{25}$

Menurut Ulama' mazhab Maliki berpendapat, bahwa harus di bedakan dari mana datangnya pemutusan pertunangan tersebut. Bila pemutusan itu dari pihak laki-laki maka ia tidak berhak menarik kembali hadiahnya sekalipun barangnya masih utuh. Bila dari pihak perempuan datangnya pemutusan, maka pihak laki-laki berhak menarik kembali hadiahnya, baik masih utuh barangnya maupun sudah habis. ${ }^{26}$

Sedangkan menurut Mazhab Syafi'I dan Hambali mengatakan, bahwa hadiah itu atau hibah itu tidak bisa ditarik kembali, karena

\footnotetext{
${ }^{24}$ Q.S. al-Isro': 34

${ }^{25}$ Ibid hal 26

${ }^{26} \mathrm{Ibid}$
} 
menurut mazhab ini sesuatu yang di hibahkan tidak dapat di tarik kembali. $^{27}$

Sumber referensi perbedaan diatas berdasrkan $:^{28}$

1. Riwayat Ashab As-Sunan, Rosulullah SAW Bersabda :

$$
\text { لا يحل للرجل أن يعطي عطية او يهب هية فيرجع فيها الا الوالد فيا يعطى ولده }
$$

Artinya : "Tidak halal orang yang telah memberikan sesuatu, atau menghibahkan sesuatu lalu meminta kembali barangnya, kecuali ayah terhadap anaknya".

2. Dari Abu Abbas, Rosulullah SAW Bersabda:

Artinya :"Orang yang menarik kembali barang yang di hibahkan, adalah laksana orang yang menarik kembali sesuatu yang di muntahkan".

3. Dari Salim dari bapaknya Rosulullah SAW Bersabda :

Artinya : Barang siapa memberikan hibah, maka ia masih tetap berhak terhadap barangnya, selama belum mendapatkan imbalannya".

Penjelasan Hadits-hadits diatas di kompromikan dalam I'lamul muwaqi'iin sebagai berikut : pemberian hibah yang tidak halal menarik kembali hibahnya, bila ia memberi hibah dengan sukarela (derma), bukan untuk imbalan. Sedangkan pemberi hibah yang tetap mempunyai hak menarik kembali hibahnya, bila hibah di berikan sebagai imbalan sesuatu yang akan diterima, tetapi ia tidak mendapatkannya. Dengan demikian hadits-hadits diatas dapat kita pakai sesuai dengan tempatnya.

Definisi hukum secara umum adalah keseluruhan peraturan tentang tingkah laku yang berlaku dalam suatu kehidupan bersama, yang dapat dipaksakan pelaksanaannya dengan suatu sanksi. ${ }^{29}$ Hukum bukan sesuatu yang sekedar menjadi bahan pengkajian secara logis dan rasional. Lebih dari itu hukum di buat untuk dijalankan dan di taati.

Sedangkan Perwujudan dari tujuan, nilai-nilai ataupun ide-ide yang terkandung didalam peraturan hukum merupakan suatu kegiatan yang tidak berdiri sendiri, tetapi mempunyai hubungan timbal balik dengan

\section{${ }^{27}$ Ibid}

${ }^{28}$ Sayyid Sabiq, Fiqh Sunnah, Juz II, al-Fatkhu lil-I'alm al-Araby, t.t., hlm. 46

29 Susdikno Mertokusumo, Mengenal Hukum: Suatu Pengantar, Yogyakarta : Liberty, 1999, hlm. 40. 
masyarakat. ${ }^{30}$ Begitu juga dengan hukum Islam, Hukum Islam dapat diartikan merupakan hukum yang bersumber dari dan menjadi bagian dari agama Islam. ${ }^{31}$

Kalau kita melihat realitas masyarakat dari sesi ekonomi maka jelas bahwa denda akibat pembatalan khitbah tersebut merupakan suatu pembebanan yang tidak bisa di berlakukan secara general. Karena hal ini terkait dengan kemampuan seseorang dalam menanggung beban keuangan.

Melihat Hukum asal dari khitbah adalah sunah, pemberian barang dalam khitbah menurut hemat penulis adalah mubah atau boleh saja. Bahkan praktek tersebut akan menjadi makruh jika hal tersebut menjadikan dampak yang tidak baik yaitu pembebanan denda ketika terjadi pembatalan khitbah oleh pihak perempuan.

Berkaitan dengan sesuatu benda yang pernah diberikan sebagai hadiah atau hibah dan dilakukan sebelum pembatalan khitbah maka sesuatu benda tersebut menjadi hak milik pihak penerima. Pihak pemberi juga tidak boleh meminta kembali sesuatu atau benda tersebut yang pernah diberikan, kecuali mahar. Secara syar'i hibah tidak boleh diminta kembali karena merupakan suatu derma yang di berikan secara sukarela dan tidak bersifat sebagai penggantian atas sesuatu.

\section{KESIMPULAN}

Perwujudan dari tujuan, nilai-nilai ataupun ide-ide yang terkandung didalam peraturan hukum merupakan suatu kegiatan yang tidak berdiri sendiri, tetapi mempunyai hubungan timbal balik dengan masyarakat. Begitu juga dengan hukum Islam, Hukum Islam dapat diartikan merupakan hukum yang bersumber dari dan menjadi bagian dari agama Islam.

Kalau kita melihat realitas masyarakat dari sesi ekonomi maka jelas bahwa denda akibat pembatalan khitbah tersebut merupakan suatu pembebanan yang tidak bisa di berlakukan secara general. Karena hal

${ }^{30}$ Eman Sulaiman, Hukum dan Perubahan Sosial (Menakar Batas Kemampuan Hukum Dalam Menghadapi Perubahan Sosial), dalam Jurnal al Ahkam Fakultas Syari'ah IAIN Walisongo Semarang, Edisi 1 April 2005, hlm. 19.

${ }^{31}$ Moh. Daud Ali, Hukum Islam, Jakarta: PT Raja Grafindo Persada, 2004, hlm. 42. 
ini terkait dengan kemampuan seseorang dalam menanggung beban keuangan.

Melihat Hukum asal dari khitbah(pinangan/lamaran) adalah sunah, pemberian barang dalam khitbah menurut hemat penulis adalah mubah atau boleh saja. Bahkan praktek tersebut akan menjadi makruh jika hal tersebut menjadikan dampak yang tidak baik yaitu pembebanan denda ketika terjadi pembatalan khitbah oleh pihak perempuan. 


\section{DAFTAR PUSTAKA}

Muhammad Yunus, Kamus Arab Indonesia, Jakarta: PT. Hidakarya Agung, hlm. 118

Sayyid Sabiq, Fiqh Sunnah, Juz II, al-Fatkhu lil-I'alm al-Araby, t.t., hlm. 138

Labib MZ. Konsep Perkawinan dalam Islam. Surabaya : Putra Jaya.2007. hal 25

Hadi Mufa'at Ahnad, Fikih Munakahat (Hukum Perkawinan Islam dan Beberapa Permasalahannya), Duta Grafika, 1992, hlm.31.

Abdurrahman, Kompilasi Hukum Islam di Indonesia, Bandung: Aka Press, 1980, hlm.114.

Abdul Hadi, Fiqih Munakahat, Semarang: Duta Grafika, Seri I, 1989, hlm.27.

Ibnu Rusyd, Bidayah al Mujtaid, jilid II, (terj), Semarang: Usaha Keluarga, t.th.,hlm.2.

Wahbah al-Zuhaily, al Fiqh al-Islam wa Adzilatuhu, Juz VII, Beirut: Dar al Fikr, t.t., hlm.10.

Djaman Nur, Fikih Munakahat, Semarang: Dina Utama, 1993, hlm.15.

Kamal Mukhtar, Asas-asas Hukum Islam Tentang Perkawinan, Jakarta: Bulan Bintang, 1993, hlm.30.

Abdullah Muhammad bin Yazid, Sunan Ibnu Majah, Juz I, Beirut: Dar al Fikr, t.t., hlm.585

Susdikno Mertokusumo, Mengenal Hukum: Suatu Pengantar, Yogyakarta : Liberty, 1999, hlm. 40.

Eman Sulaiman, Hukum dan Perubahan Sosial (Menakar Batas Kemampuan Hukum Dalam Menghadapi Perubahan Sosial), dalam Jurnal al Ahkam Fakultas Syari'ah IAIN Walisongo Semarang, Edisi 1 April 2005, hlm. 19.

Moh. Daud Ali, Hukum Islam, Jakarta: PT Raja Grafindo Persada, 2004, hlm. 42.

http://www.kompasiana.com. Diakses 01 Mei 2019 